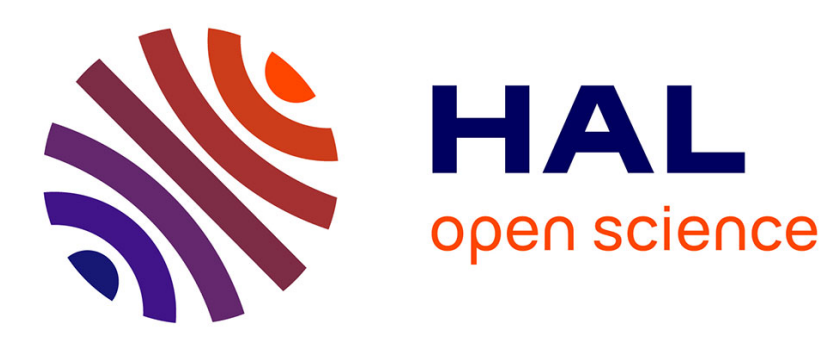

\title{
On optimality in intergenerational risk sharing
}

Gabrielle Demange

\section{To cite this version:}

Gabrielle Demange. On optimality in intergenerational risk sharing. Economic Theory, 2001, 20 (1), pp.1-27. 10.1007/s001990100199 . halshs-00581414

\section{HAL Id: halshs-00581414 https://shs.hal.science/halshs-00581414}

Submitted on 30 Mar 2011

HAL is a multi-disciplinary open access archive for the deposit and dissemination of scientific research documents, whether they are published or not. The documents may come from teaching and research institutions in France or abroad, or from public or private research centers.
L'archive ouverte pluridisciplinaire HAL, est destinée au dépôt et à la diffusion de documents scientifiques de niveau recherche, publiés ou non, émanant des établissements d'enseignement et de recherche français ou étrangers, des laboratoires publics ou privés. 


\title{
On optimality of intergenerational risk sharing ${ }^{1}$
}

\author{
Gabrielle Demange \\ DELTA, 48 Boulevard Jourdan, Paris 14, \\ 75014 France e-mail: demange@delta.ens.fr
}

March 22, 2001

\begin{abstract}
This paper defines and studies optimality in a dynamic stochastic economy with finitely lived agents, and investigates the optimality properties of an equilibrium with or without sequentially complete markets. Various Pareto optimality concepts are considered, including interim and ex ante optimality. We show that, at an equilibrium with a productive asset (land) and sequentially complete markets, the intervention of a government may be justified, but only to improve risk sharing between generations. If markets are incomplete, constrained interim optimality is investigated in two-period lived OLG economies. We extend the optimality properties of an equilibrium with land and examine conditions under which introducing a pay-as-you-go system would not lead to any Pareto improvement upon an equilibrium.
\end{abstract}

Keywords and Phrases: overlapping generations, incomplete markets, optimality

JEL Classification Numbers: D52, D61, H55

\footnotetext{
${ }^{1}$ thank Subir Chattopadhyay and Bruno Jullien for helpful comments.
} 


\section{Introduction}

Intergenerational transfers are of crucial importance, as illustrated by the current debates on Social Security. Their theoretical analysis has been tackled in risk-free economies with two period-lived overlapping generations (Samuelson [15], Gale [8], Diamond [7]). Two striking results have been shown. First, a competitive equilibrium may be inefficient. At a steady state equilibrium, inefficiency is characterized by an interest rate less than the population growth, which is associated with an overaccumulation of capital in a production economy. In such a situation, direct transfers from the young to the old agents, as performed either by a pay as you go system or by a governmental debt, make every generation better off, the current old included. Second, inefficiency is ruled out at equilibrium if there exists a durable asset, land, that distributes positive dividends at all dates. Our purpose is to study how such results extend to stochastic economies with finitely lived agents. Endowments, land dividends, and production are subject to shocks, and markets may be (sequentially) incomplete. Risk sharing is then an important issue which may interact with overaccumulation. Moreover, since rates of return are not equalized across different securities, it is unclear which rate should be compared with population growth to assess efficiency.

To investigate efficiency issues, we focus on the Pareto concept, which takes into account all the agents in the economy. ${ }^{2}$ In our stochastic set up, in which different events are possible before an agent's birth, Pareto optimality may however be defined in many different ways. A first natural concept is interim optimality, in which an agent's utility level is evaluated in all the possible circumstances at his birth's date, taking into account the available information at that date. Intuitively, this concept is rather weak: since an agent's utility level is evaluated at birth, it does not account for the possibilities of insurance across the events that may occur at that date. A second concept, ex ante optimality, by evaluating the agents' welfare at the initial date, takes full account of these insurance possibilities. More generally a family of Pareto concepts may be defined according to the dates at which agents' welfare is evaluated, and the information available at those dates.

Given a Pareto concept and possibly some constraints on consumption plans, we investigate necessary or sufficient conditions for optimality. To be optimal, an allocation must be short run optimal: the agents born before a given date cannot be made some better off and other at least as well off without changing the allocation of the agents born after that date (where agents' welfare is evaluated according to the chosen concept). Short run optimality however is not sufficient for optimality. The usual approach, which yields the interest rate condition (for a survey see Geanakoplos-Polemarchakis [9]), extends to our

\footnotetext{
${ }^{2}$ In risk-free economies, a weaker concept in which the utility levels of all but a finite number of generations are considered, is sometimes used to evaluate "long run situations". For example, in Samuelson model, any stationary allocation that is sustained by an interest rate strictly above the population growth is Pareto optimal but not optimal in the long run: a transition to the golden rule would make future generations better off but surely some generations would suffer from the reform.
} 
stochastic economies with constraints on consumption plans but only under appropriate convexity assumptions. Such assumptions ensure that a short run optimal allocation is supported by at least one contingent value process (which is the unique, up to a normalization, Arrow-Debreu supporting price process if consumption plans are not constrained). A single condition guarantees the optimality of a short run optimal allocation. Take the infimum, over all supporting processes, of the expected present value of one unit of wealth for sure at a future date $t$; the condition says that this infimum converges to zero when $t$ increases up to infinity.

We then investigate the optimality of an equilibrium with rational expectations when a durable asset, land, is transacted, and possibly some financial securites. Add the additional, and not innocuous, assumption of sequentially complete markets. Using the above condition easily yields a clear-cut result: whatever optimality concept, if an equilibrium with land is short run optimal, then it is optimal as well. Accordingly, the main issue is short run optimality. Recall that, with sequentially complete markets, each agent can fully insure against the realization of the shocks that are realized after his birth and conditionally on the state at his birth. Therefore, short run interim optimality is guaranteed at equilibrium, and as a consequence optimality as well. This may be a striking result since high fluctuations in land prices may occur at equilibrium. Now, markets, even sequentially complete, do not allow for insurance against the events at birth. If one is concerned with these risks, a stronger optimality concept must be used, and short run optimality is not guaranteed at all. From a positive point of view, under the stated assumptions, the intervention of a government may be justified, but only to improve risk sharing between generations.

If markets are not sequentially complete, the optimality properties of an equilibrium are much more difficult to study. Implementing some transfers induces changes in the demand for the assets, hence their prices. If there is a long lived asset such as land, the changes in its future prices affect the sharing possibilities, i.e. modifies the "spanning". As a result, the convexity of consumption sets alluded above is not satisfied, so that a short run optimal allocation is typically not supported by a contingent value process, and the standard approach is not helpful. We however obtain some positive results in two period life overlapping generations economies. Keeping the financial securities payoffs fixed, we examine whether an equilibrium can be Pareto improved upon, in the interim sense, when these securities and the good can be reallocated among the young agents before the exchanges. If no improvement is possible, the equilibrium is "second best" or "constrained" optimal, since the constraints imposed by the incomplete market structure are taken into account. Two cases are considered, with or without productive land.

If there is productive land, and no short sales on land, the results are clear: equilibria are not comparable, or equivalently all are constrained interim optimal : a planner cannot by appropriate reallocation improve strictly the situation of some agents at birth without making some other worse off. Loosely speaking, productive land is still, even without complete markets, an efficient tool to exchange goods over time among generations. 
Without productive land, another efficient tool may be a pay-as-you-go system, as is the case in risk-less Samuelson economies if the interest rate is less than population growth. Introducing such a system in an incomplete asset structure enlarges the spanning so again the standard approach is not helpful. A simple condition, which bears on the returns of the financial securities, nevertheless ensures that the autarkic equilibrium is constrained interim optimal, meaning that no pay-as-you-go Social Security with pensions proportional to past contributions, even coupled with reallocations of the securities, leads to a Pareto improvement.

Whereas limited to a set up where agents live for two periods only, both results suggest that if land is transacted or if a condition on financial returns is satisfied, which is likely to be true in our economies, the source of Pareto improvement should be found more on risk sharing considerations rather than on positive transfers from the young to the old agents.

The literature on stochastic overlapping generation economies starts with Muench [11], Peled [13], and Aiyagari-Peled [3], who consider stationary environments, where shocks are described by an exogenous state variable. In this set up, they focus on time invariant allocations, and characterize those which are conditionally optimal, i.e. Pareto optimal among time invariant allocations. We show that conditional and interim optimality are closely related, and that our results extend theirs to a more general set up. Demange-Laroque [6] and Chattopadhyay-Gottardi [15] have also obtained similar results by different methods. Abel-Mankiw-Summers-Zeckhauser [1] provide a sufficient condition for interim optimality in a two period lived representative generation model and apply it to the United States. Theorem 4 extends their condition to an economy without a representative agent nor sequentially complete markets. Finally another branch of the literature, Zilcha [16],[17], concentrates on capital efficiency, independently of risk sharing considerations. The objective is to check whether overaccumulation can be defined unambiguously, independently of utility functions.

The paper is organized as follows. Section 2 sets up the model. Section 3 defines optimality concepts, gives sufficient conditions for an allocation to be optimal, and draws some comparisons with conditional optimality. Section 4 studies the optimality properties of a rational expectations equilibrium when markets are sequentially complete. When markets are incomplete, the same question is tackled in Section 5 in two period lived overlapping generations economies. Proofs are gathered in section 6 .

\section{The Model}

\subsection{The economy}

We consider an economy starting from date 0 up to infinity. In every period, there is a single physical good which can be used for consumption and investment.

Agents. There is an infinity of agents who each one lives for a finite period of time, which is uniformly bounded by some $\ell$ : agent $i$ is born at date $t_{i}$ and dies 
at date $T_{i}$ with $T_{i}-t_{i}+1 \leq \ell$. Agent $i$ 's preferences over his lifetime consumption $c_{i}=\left(c_{i, t}, t=t_{i}, \ldots, T_{i}\right)$ are represented by a Von Neumann-Morgenstern utility function $u_{i}\left(c_{i}\right)$. If agent $i$ is alive at date 0 and was born before, his utility levels are evaluated over consumption from date 0 on, taking past consumption levels as given; it will be convenient to set $t_{i}$ equal to zero.

The whole set of agents is denoted by $\mathcal{I}$ and the subset of agents who are born before $t$ by $\mathcal{I}_{t}$. The number of agents alive at a given date is assumed to be uniformly bounded ${ }^{3}$ moreover, to ensure some intertemporal trades, for any two consecutive dates, there is at least one agent alive at both dates. A typical example is an overlapping generations (OLG) model in which at each date a new generation of $M$ types agents is born and lives for $\ell$ periods; an agent is then naturally indexed by his birth's date and type.

Resources and production. At each date $t$, there are some aggregate resources $\omega_{t}$ on top of the returns from previous investment. The good can be consumed or invested in a stochastic production technology : $k$ units invested at date $t$ yield $f\left(k, \rho_{t+1}\right)$ units at $t+1$ where $\rho_{t+1}$ is the shock realized at $t+1$.

The uncertainty. The economy is subject at each date $t, t \geq 1$, to exogenous shocks, which are described by a variable $s_{t}$. To avoid technical difficulties, the stochastic process $s_{t}$ is assumed to take its value in a finite fixed set $S$. A state of the world ${ }^{4}$ at $t, s^{t}$, is the sequence of realized shocks up to $t: s^{t}=\left(s_{0}, s_{1}, \ldots, s_{t}\right)$, where $s_{0}$ includes all relevant information on the past. All the variables that describe the economy such as endowments, productivity shocks, are functions of these states. The transition probability of the process $s^{t}$ is denoted by $P$ : $P\left(s_{t+1} \mid s^{t}\right)$ gives the probability of $s_{t+1}$ given $s^{t}$.

Public information. The information on the state of the world that becomes public is used by a "planner" to evaluate the agents' welfare. Information at date $t$ is described as usual by a partition of the set of states $S^{t}$ : it is known to which element $h^{t}$ of this partition the realized state $s^{t}$ belongs; $h^{t}$ will be called the history at time $t$. As usual, information is increasing, and the probability distribution of the process $h^{t}$ is deduced from probability $P$. We shall denote $h^{t+1} \succ h^{t}$ if $h^{t+1}$ is a history that follows $h^{t}$ with positive probability.

Assumptions Throughout the paper, we make the following assumptions :

- Inada conditions : $\frac{\partial u_{i}}{\partial c_{i, t}}$ tends to infinity if $c_{i, t}$ tends to zero for $t=t_{i}, \ldots, T_{i}$;

- the process $\omega_{t}$ is strictly positive at all dates, and uniformly bounded above: there is $\bar{\omega}$ such that $\omega_{t} \leq \bar{\omega}$ any $t$.

- for any possible $\rho, k \rightarrow f(k, \rho)$ is defined for all $k \geq 0$; it is null for $k=0$, nondecreasing, concave, differentiable, and $\frac{\partial f(k, \rho)}{\partial k} \leq r<1$ for any $k$ high enough, any $\rho$.

These assumptions are standard. They allow us to restrict attention on interior and bounded allocations. ${ }^{5}$ Production is performed with nonincreasing returns to scale, and may be null.

\footnotetext{
${ }^{3}$ This assumption precludes population growth but could be relaxed.

${ }^{4} \mathrm{~A}$ state of the world is sometimes called "node" or "date-event" in the literature since the uncertainty may be described by a date-event tree.

${ }^{5}$ There is $\bar{k}$ such that $f(k+\bar{\omega}, \rho) \leq r k$ for any $k \geq \bar{k}$, any $\rho$. Whatever initial value, even if the good is invested for sure at all dates, the returns get almost surely in finite time lower than $\bar{k}$. As a result, aggregate resources are bounded.
} 


\section{$2.2 \quad$ Allocations}

We are interested in situations where an allocation that satisfies both measurability and scarcity constraints is not necessarily feasible, due to lack of information, constraints on financial securities and redistributive tools. To cope with such situations, the set of agents' consumption plans may be restricted.

Feasible consumption plans. A consumption plan for agent $i$ is a stochastic process $c_{i}=\left(c_{i, t}\right)$, where $c_{i, t}$ is the random positive consumption of $i$ at date $t, t_{i} \leq t \leq T_{i}$, where $c_{i, t}$ is measurable with respect to the fundamental states $s^{t}$; accordingly $c_{i, t}$ may be written as $\left(c_{i, t}\left(s^{t}\right)\right)$. The whole set of unconstrained $i$ 's consumption plans will be denoted by $X_{i}$. Under constraints, the set of $i$ 's consumption plans is described by a subset $C_{i}$ of $X_{i}$. Note that, since $C_{i}$ is a set of consumption plans, the constraints bear on life time consumption plans and may depend on the state of the world.

An allocation $\mathbf{c}=\left(c_{i}, i \in \mathcal{I}\right)$, specifies the consumption plans for all agents. Aggregate consumption at time $t$, denoted by $c_{t}$, is equal to $\sum_{i} c_{i, t}$ where $i$ runs over the agents who are alive at $t$. We are now able to define the feasible allocations, given the constraints.

Definition 1 Given the collection of sets $\mathbf{C}=\left(C_{i}, i \in \mathcal{I}\right)$, an allocation $\mathbf{c}=$ $\left(c_{i}, i \in \mathcal{I}\right)$ is $\mathbf{C}$-feasible if $c_{i} \in C_{i}$ for all $i$, and the scarcity constraints are met at every date, every state: There is a non negative process, $k_{t}$, measurable with respect to public information, starting at $k_{-1}$ such that :

$$
c_{t}+k_{t}=f\left(k_{t-1}, \rho_{t}\right)+\omega_{t} \text { for all } t \geq 0 .
$$

Investment is assumed to be measurable with respect to public information, for simplicity. This assumption could be easily modified.

\subsection{Optimality concepts}

Two considerations motivate our definitions. First, constraints have to be taken into account : given the sets $\mathbf{C}$, we only compare $\mathbf{C}$-feasible allocations among each others. ${ }^{6}$ Secondly, under uncertainty, an individual's expected utility level much depends on the date at which is evaluated, and on the available information. As a consequence, various Pareto optimality concepts are obtained according to the dates that are chosen to evaluate individuals' welfare. Before giving a general definition, we spell out two special but prominent cases, hereafter called interim and ex ante optimality.

Definition 2 A C-feasible allocation $\mathbf{c}$ is interim optimal if there is no other C-feasible allocation $\mathbf{c}^{\prime}$ such that, for all $i$, all histories $h$ at date $t^{i}$ :

$$
E\left[u_{i}\left(c_{i}^{\prime}\right) \mid h\right] \geq E\left[u_{i}\left(c_{i}\right) \mid h\right],
$$

with a strict inequality for at least one $(i, h)$.

\footnotetext{
${ }^{6}$ This is similar to constrained efficiency such as considered in the incomplete markets literature, for example in Geanakoplos-Polemarchakis [8].
} 
Agents' utility levels are evaluated in all possible circumstances that may occur at their birth's date. Roughly speaking, to check the optimality of an allocation, one needs to consider all possible paths that the economy may follow starting from an initial situation, and looks whether it is possible to make some agents better off and no one worse off along these paths. This concept may be thought to be rather weak (see however the comments hereafter). Since it distinguishes the same agent born in different states, it does not account for the possibilities of insurance across the events that may occur at that date. Ex ante optimality, that we now define, takes full account of these insurance possibilities.

Definition 3 A C-feasible allocation $\mathbf{c}$ is ex ante optimal if there is no other C-feasible allocation $\mathbf{c}^{\prime}$ such that, for all $i$ :

$$
E\left[u_{i}\left(c_{i}^{\prime}\right) \mid h^{0}\right] \geq E\left[u_{i}\left(c_{i}\right) \mid h^{0}\right],
$$

with a strict inequality for at least one $i$.

Ex ante optimality implies interim optimality, and is much stronger indeed. Actually ex ante optimality and interim optimality are the polar cases of a family of concepts that we now define. Each concept is characterized by $\mathbf{e}=$ $\left(e_{i}, i \in \mathcal{I}\right)$, which gives the date $e_{i}, 0 \leq e_{i} \leq t_{i}$, at which each agent $i$ 's utility level is evaluated.

Definition 4 Given $\mathbf{e}$, a $\mathbf{C}$-feasible allocation $\mathbf{c}$ is (e, C)-optimal if there is no other $\mathbf{C}$-feasible allocation $\mathbf{c}^{\prime}$ such that, for all $i$, all histories $h$ at date $e_{i}$ :

$$
E\left[u_{i}\left(c_{i}^{\prime}\right) \mid h\right] \geq E\left[u_{i}\left(c_{i}\right) \mid h\right],
$$

with a strict inequality for at least one $(i, h)$.

Interim and ex ante optimality correspond respectively to the cases where $e_{i}=$ $t_{i}$ for all $i$, and $e_{i}=0$ for all $i$. The earlier the evaluation dates, the stronger the concept since more insurance possibilities are taken into account. Note that, in a deterministic set up, all concepts collapse to a single one, the usual Pareto optimality concept applied to all agents, including those who were born before date 0 . Finally, if all the inequalities are satisfied, say in definition 2, we say that $\mathbf{c}^{\prime}$ interim dominates $\mathbf{c}$.

\section{Conditions for optimality}

To study optimality, it is tempting to consider an artificial economy where agents are the pairs $(i, h)$ in which $h$ is a possible history at $e_{i}$. This is possible since, thanks to the Von Neumann-Morgenstern assumption, $i$ 's utility level given $h$ depends on a consumption plan only through its restriction to the states that succeed $h$. Under appropriate assumptions, we provide some necessary or sufficient conditions for optimality, by following similar arguments as those previously developed in OLG models with certainty (for a survey see Geanakoplos-Polemarchakis [9]). 


\subsection{Short run optimality}

Given an optimality concept, i.e. given evaluation dates $\mathbf{e}$ and sets $\mathbf{C}$, optimality requires short run optimality, which asserts that no reallocation among a finite set of agents can improve their situation. Equivalently, the agents who are born before some date $t$, i.e. members of $\mathcal{I}_{t}$, cannot be made all not worse off and some better off without modifying the consumption plans of some agents who are born after $t$ :

A $\mathbf{C}$-feasible allocation $\mathbf{c}=\left(c_{i}\right)$ is $(\mathbf{e}, \mathbf{C})$-optimal for $\mathcal{I}_{t}$, if there is no $\mathbf{C}$-feasible $\mathbf{c}^{\prime}=\left(c_{i}^{\prime}\right)$ such that

1. for any $i$ in $\mathcal{I}_{t}$, for any $h$ at date $e_{i}: E\left[u_{i}\left(c_{i}^{\prime}\right) \mid h\right] \geq E\left[u_{i}\left(c_{i}\right) \mid h\right]$, with a strict inequality for at least one $(i, h)$

2. $c_{i}^{\prime}=c_{i}$ for any $i$ born after $t$.

It is short run $(\mathbf{e}, \mathbf{C})$-optimal if it is $(\mathbf{e}, \mathbf{C})$-optimal for all $\mathcal{I}_{t}, t \geq 0$.

Whereas short run optimality is necessary for optimality, it is not sufficient since, as first shown by Samuelson [15], some transfers involving all generations can make all of them better off. In risk-free economies, the optimality of a short run optimal allocation is guaranteed by a condition on the supporting interest rates. In order to extend such condition, one may consider a process that implicitly supports a short run optimal allocation, if it exists.

Given a consumption plan $c_{i}$ in $C_{i}$, a possible history $h$ at date $e_{i}$, let $c_{i, h}$ be the "restriction" of $c_{i}$ to the states that succeed $h$, i.e. $c_{i, h}$ is the consumption plan that coincides with $c_{i}$ for those states and is equal to zero otherwise. ${ }^{7}$ Also denote by $C_{i, h}$ the obtained set. Note that $E\left[u_{i}\left(c_{i}\right) \mid h\right]=E\left[u_{i}\left(c_{i, h}\right) \mid h\right]$.

A process $Q=\left(Q_{\tau}, \tau=0, \ldots\right)$, where $Q_{\tau}$ is measurable with respect to $s^{\tau}$, positive, is called a valuation process. Let . denote the scalar product. Then

$$
E\left[Q . c_{i, h}\right]=E\left[\sum_{\tau=t_{i}}^{\tau=T_{i}} \sum_{s^{\tau} \succ h} Q_{\tau} c_{i, \tau}\left(s^{\tau}\right)\right],
$$

is equal to the expected value weighted by $Q$ of $i^{\prime} s$ consumption plan following history $h, c_{i, h}$.

Definition 5 A valuation process $Q$ supports the allocation $\mathbf{c}$ for $\mathcal{I}_{t}$ if

1. for any $i$ who is born before $t$, any $c_{i}^{\prime} \in C_{i}$, any history $h$ at date $e_{i}$,

$$
\text { if } E\left[u_{i}\left(c_{i}^{\prime}\right) \mid h\right]>E\left[u_{i}\left(c_{i}\right) \mid h\right] \text { then } E\left[Q . c_{i, h}^{\prime}\right]>E\left[Q . c_{i, h}\right]
$$

2. for any $\tau<\max _{i \in \mathcal{I}_{t}} T_{i}$, any history $h$ at date $\tau$,

$$
k_{\tau} \text { maximizes } E\left[Q_{\tau+1} f\left(k, \rho_{\tau+1}\right)-Q_{\tau} k \mid h\right]
$$

\footnotetext{
${ }^{7}$ Formally $c_{i, h, t}\left(s^{t}\right)=c_{i, t}\left(s^{t}\right)$ if $s^{t}$ succeeds $h$ and zero otherwise. When $h$ runs over all possible histories at date $e_{i}$, a partition of all possible events during $i^{\prime} s$ life is obtained, so that $c_{i}$ is characterized by its restrictions $c_{i, h}$ over all possible histories $h$ at date $e_{i}$.
} 
Conditions 1 and 2 bear on the consumption plans of the agents born before $t$, so that they impose no restriction later than $\max _{i \in \mathcal{I}_{t}} T_{i}$. They depend both on the consumption sets and evaluation dates of these agents. The larger the space spanned by $C_{i}$, the earlier the evaluation date $e_{i}$, the more stringent condition 1 is. If a supporting process exists for any $\mathcal{I}_{t}$, the allocation is clearly short run optimal, but the converse is not necessarily true, except under additional assumptions.

Assumption A1 For each $i$

(i) a consumption plan $c_{i}$ is feasible if and only if, for each history $h$ at date $e_{i}$, its restriction $c_{i, h}$ belongs to $C_{i, h}$. Equivalently, $C_{i}=\Pi C_{i, h}$, the product over all histories $h$ at date $e_{i}$,

(ii) the sets $C_{i, h}$ are convex,

(iii) let $i$ live at $t$ and $h^{t}$ be a history that follows $h$ at $t$; if $c_{i, h}$ belongs to $C_{i, h}$, for $\varepsilon$ small enough, $c_{i, h}+\varepsilon \mathbb{1}\left(h^{t}\right)$ belongs to $C_{i, h}$, where $\mathbb{1}\left(h^{t}\right)$ is equal to 1 at date $t$ in history $h^{t}$ and zero otherwise.

By condition $(i)$, the constraints that bear on $i$ 's consumption plans are independent across the possible histories at the evaluation date, a mild assumption since $i$ 's welfare is evaluated before birth. Assumption (ii), which is standard in microeconomic theory, is not innocuous in our set up, as we shall see in section 4 . Under condition ( $i i i)$, consumption at a given date can be modified by a small amount in any event that is publicly observable; constraints on consumption sets are therefore linked to a lack of public information since, with full information, a consumption plan can be (locally) modified in any state. Using that whatever two consecutive dates there is always an agent alive at both dates, condition (iii) ensures that the economy satisfies a resource relatedness assumption, which is necessary to get the existence of supporting prices.

We normalize value processes, which are defined up to a multiplicative constant, by picking an agent who is alive at date 0 , say agent 1 , and by requiring the condition $E\left[Q \cdot c_{1}\right]=1$. Let $\mathcal{Q}_{t}$ be the set of normalized processes that support the allocation $\mathbf{c}$ up to $t$.

Proposition The sets $\mathcal{Q}_{t}$ are decreasing : $\mathcal{Q}_{t+1} \subset \mathcal{Q}_{t}$, any $t$. Under $A 1, a$ C-feasible allocation is $\mathcal{I}_{t}$-optimal if and only if there is a process that supports it for $\mathcal{I}_{t}$, i.e. if $\mathcal{Q}_{t}$ is nonempty.

The proof follows from standard separation arguments applied to an artificial economy where agents are the pairs $(i, h)$ in which $i$ is born before $t$ and $h$ is a possible history at the date where $i$ 's utility is evaluated. ${ }^{8}$

Example 1. Let us consider an exchange economy with full information and no constraints on consumption plans $\left(C_{i}=X_{i}\right.$ for all $\left.i\right)$. Short run interim

\footnotetext{
${ }^{8}$ Aliprantis-Brown-Burkinshaw [2] study the existence of a price process that supports a short run optimal allocation (called Malinvaud optimal) for each $t$, i.e. with our notation an element in the intersection of the $\mathcal{Q}_{t}$. Their results are obtained in an OLG model with an infinite dimensional commodity space and a finite number of agents each period. Presumably they could be used to handle an infinite state space, with the difficulty that, in our model, an infinite state space typically induces an infinite number of agents each period in our artificial economy.
} 
optimality is then equivalent to the equalization of the marginal rates of substitution between current and next period's consumption across the agents alive at those dates $:^{9}$ for any $s^{t}$, any $s^{t+1}=\left(s^{t}, s_{t+1}\right)$, there is a positive value, denoted by $\operatorname{mrs}\left(s^{t+1} \mid s^{t}\right)$, such that for any individual $i$ who is alive at date $t$ and date $t+1$ :

$$
E\left[\frac{\partial u_{i}\left(c_{i}\right)}{\partial c_{i, t+1}} \mid s^{t+1}\right] / E\left[\frac{\partial u_{i}\left(c_{i}\right)}{\partial c_{i, t}} \mid s^{t}\right]=\operatorname{mrs}\left(s^{t+1} \mid s^{t}\right) .
$$

A supporting process is unique, defined recursively by $E\left[Q \cdot c_{1}\right]=1$ and the formula:

$$
Q_{t+1}\left(s^{t+1}\right)=Q_{t}\left(s^{t}\right) \operatorname{mrs}\left(s^{t+1} \mid s^{t}\right) .
$$

Now let us consider, instead of interim optimality, the stronger ex ante optimality concept. While the above conditions are necessary, but there are no longer sufficient: the marginal rates of substitution between consumption in different states at birth should be proportional to $Q$.

\subsection{Sufficient conditions for optimality}

We show here that, whatever optimality concept is used, a single condition guarantees the optimality of a short run optimal allocation.

Theorem 1 Let the evaluation dates $\mathbf{e}$ and the sets $\mathbf{C}$ be given, and assume A1. A short run $(\mathbf{e}, \mathbf{C})$-optimal allocation is $(\mathbf{e}, \mathbf{C})$-optimal if

$$
\lim _{t \rightarrow \infty} \inf _{Q \in \mathcal{Q}_{t}} E\left[\sum_{\tau=t+1}^{t=t+\ell} Q_{\tau}\right]=0 .
$$

With full information and no constraints on consumption plans as in example 1 above, $Q_{t}$ is a singleton. Condition (S) is then equivalent to $\lim _{t \rightarrow \infty} E\left[Q_{t}\right]=$ 0 , and the usual argument works as follows. Start with a short run optimal allocation. To (weakly) improve the situation the agents who are born before $t$, these agents must receive some aggregate transfers that have a positive value under $Q$. These transfers can only be given by the generations born between $t+1$ and $t+\ell$, and are therefore bounded. Moreover, if no agent is to be made not worse off, the value of the transfers to agents born before $t$ does not decrease with $t$. Condition (S) implies however that such value converges to zero, hence is zero at all dates. If consumption plans are constrained, the same type of argument can be used by considering the whole set of processes that support a short run optimal allocation. ${ }^{10}$ Note also that condition (S) is surely met if the value of aggregate wealth is finite for some supporting process (the finite value condition has been introduced by Wilson [15]).

\footnotetext{
${ }^{9}$ Borch [4] has been the first to show that optimal risk sharing implies such conditions. Of course, $\operatorname{mrs}\left(s^{t+1} \mid s^{t}\right)$ multiplied by the transition probability $P\left(s_{t+1} \mid s^{t}\right)$ is the implicit Arrow Debreu price of one consumption unit available at date $t+1$ contingent on the realization of $s_{t+1}$ in terms of the good at $t$ if $s^{t}$ is the state of the world.

${ }^{10}$ Some technical care is needed because a value process is unconstrained on the space orthogonal to feasible consumption plans; as a result the value of transfers computed at a given supporting process may be unbounded.
} 
Theorem 1 can be readily applied to an OLG economy with a two period lived representative agent as considered by Abel and alii [1]. They consider an equilibrium, assuming that an infinitely lived asset distributes (random) dividends, $d_{t}$ at $t$. They show that if the asset price $p_{t}$ does not converge to zero, and satisfy for some $\varepsilon>0: d_{t}>\varepsilon p_{t}$ in all periods and all states of natures, then the equilibrium is interim optimal. To see that Theorem 1 applies, note that, with a two period-lived representative generation, short run interim optimality holds at equilibrium (production decisions are optimal and no risk sharing can take place). A supporting process is defined recursively by (2) where $\operatorname{mrs}\left(. \mid s^{t}\right)$ is the marginal rate of substitution of the representative agent born in period $t$, state $s^{t}$. Therefore, the asset price satisfies

$$
\left.\left(Q_{t} p_{t}\right)\left(s^{t}\right)=E\left[Q_{t+1}\left(p_{t+1}+d_{t+1}\right) \mid s^{t}\right)\right] \geq(1+\epsilon) E\left[Q_{t+1} p_{t+1} \mid s^{t}\right] .
$$

Iteration and expectation imply that condition $(\mathrm{S})$ is met.

According to Abel and alii [1], the above dividend condition is satisfied in the United States. One question however is whether such a condition is still sufficient for optimality with an heterogeneous population, and/or agents who live for more than two periods. We shall investigate this question in sections 4 and 5 .

Condition $(\mathrm{S})$ is not necessary. For example in a risk-free economy, a stationary allocation is optimal whenever the interest rate is non negative whereas $(\mathrm{S})$ is satisfied only if the interest rate is strictly positive. Under additional conditions on utility and production functions, condition (S) can be weakened somewhat. That we need such assumptions is already known from risk-free economies (see Okuno-Zilcha [12] who obtain a full characterization ${ }^{11}$ ).

Assumptions A2. Utility functions are twice differentiable with a uniformly bounded Hessian: for some positive $\alpha$, for any $i$ any $c$

$$
-x^{\prime} u_{i}^{\prime \prime}(c) x \leq \alpha\|x\|^{2}
$$

$\partial u_{i} / \partial c_{i, t}$ is uniformly bounded at $\mathbf{c}$

$f$ is twice differentiable with respect to $k$; if $\bar{k}$ is a bound on investment, there is $\beta>0$ such that $-f " k, k(k, \rho) \geq \beta$ for any $k \leq \bar{k}$, any $\rho$.

Theorem $\mathbf{2}$ Let the evaluation dates $\mathbf{e}$ and the sets $\mathbf{C}$ be given, and assume $A 1$ and $A 2$. A bounded, short run $(\mathbf{e}, \mathbf{C})$-optimal allocation is $(\mathbf{e}, \mathbf{C})$-optimal if for some $K$, any $t$

$$
\inf _{Q \in \mathcal{Q}_{t}} E\left[\sum_{\tau=t+1}^{t=t+\ell} Q_{\tau}\right] \leq K .
$$

\footnotetext{
${ }^{11}$ Such a characterization has been extended by Chattopadhyay-Gottardi [5] in a two period lived OLG economy with multiple goods. They consider the interim optimality of an equilibrium with sequentially complete markets (actually, they use the terminology of conditional optimality, which we have rather used for stationary allocations that are conditioned on some states as defined in the next subsection). As should be clear (see also Section 4), with sequentially complete markets, an equilibrium is short run interim optimal. An interesting practical feature of our formulation is that it can be easily checked, while their criterion is rather cumbersome. The criterion involves the convergence of an infinite weighted sum of the inverse of prices in which the weights depend on preferences.
} 
Without assumptions A2, for example with risk neutral agents, there are examples where $(\mathrm{W})$ is met but the allocation is not optimal.

\subsection{Time invariant economies and conditional optimality}

In two period OLG economies that are subject to some time invariant Markov exogenous state of nature, it is quite natural to focus on time invariant allocations. This approach, initiated by Muench (1977), leads to consider conditional optimality, which amounts to compare time invariant allocations among each others, as defined below. We first state conditions (S) and (W) for a time invariant allocation in such economies, and then compare our results with the characterization of conditional optimality obtained by Aiayagari-Peled (1991).

In a two period OLG exchange economy, assume that the state of nature ${ }^{12}$ $s$ follows a finite first order Markov process with time invariant transition probabilities $\pi\left(s^{\prime} \mid s\right)$. At each date $t, t \geq 1$, a new two-period lived generation is born, each of which consists of $M$ agents of type $m=1, \ldots, M$. Except for the old agents alive at the initial date, agents are indexed by their birth's date and type.

An allocation is time invariant if, given his type, the consumption plans of an agent depend on time only through the states of nature that are realized during his life. It is therefore characterized by the consumption of the initial old agents, and state dependent consumption for each type $m:\left(c_{m}^{y}(s), c_{m}^{o}\left(s, s^{\prime}\right), s \in\right.$ $\left.S, s^{\prime} \in S\right)$, which give the consumption plans a type $h$ agent if $s$ is realized when young, and $s^{\prime}$ when old.

With full information and no constraint on consumption sets, this economy is a particular case of example 1. Short run interim optimality is therefore equivalent to the equalization of the marginal rates of substitution across the living agents, and a supporting price process is defined by (2). Since marginal rates of substitution inherit the time invariance property of the allocation, this identical value writes as $\operatorname{mrs}\left(s^{\prime} \mid s\right)$ where $s=s_{\tau}$ and $s^{\prime}=s_{\tau+1}$ are the states of nature realized at $\tau$ and $\tau+1$. Conditions (S) and (W) may be stated in terms of the square matrix $B=\left(\pi\left(s^{\prime} \mid s\right) \operatorname{mrs}\left(s^{\prime} \mid s\right)\right)$ :

Condition $(S)$ (resp. $(W)$ ) is equivalent to the dominant root of the square positive matrix $B$ to be strictly less (resp. less) than $1 .{ }^{13}$

In this set up, a time invariant allocation is conditionally optimal if it is not possible to increase the expected utility of the agents born in some state of

\footnotetext{
${ }^{12}$ Note that we use the word state of nature and not state of the world. For the moment it is enough to think of $s$ as the fundamental shock that determines current resources, but see below for some precision. Also the analysis can be extended to the case where $s$ reflects preference shocks.

${ }^{13}$ To see this, let denote $S=\left(s^{1}, . ., s^{k}, . . s^{n}\right)$ the set of states, and $\mathbf{1}$ be the $n$-vector with all components equal to 1 . Simple computation shows that $E\left[Q_{t} \mid s_{0}=s^{k}\right]$, the expectation of the supporting price conditional on the initial state to be $s^{k}$, is equal, up to a constant, to the $k$-th component of the $n$-vector $B^{t} \mathbf{1}$. Since all elements of $A$ are positive, it is well known that $B^{t} \mathbf{1}$ converges to 0 (resp. is bounded) if and only if $B$ has its dominant eigenvalue strictly less (resp. not larger) than 1.
} 
nature without lowering that of the agents born in some other state. ${ }^{14}$ Clearly interim optimality implies conditional optimality but the converse is not clear. Aiayagari-Peled (1991) show that a short run optimal time invariant allocation is conditionally optimal if and only if the dominant root of the square positive matrix $B$ is less than or equal to 1 . Using the previous results, a conditionally optimal time invariant allocation is also interim optimal : it is dominated by no feasible allocation, time invariant or not. Therefore both concepts coincide.

This result is interesting for the following reason. Conditional optimality is defined with respect to an a priori state space which looks rather arbitrary. If $s$ is the "fundamental" state at each date, the state may be enlarged, for example by including past realizations of the state or a sunspot variable (still keeping the first order Markov assumption). A natural question is whether, starting from an allocation that is conditionally optimal with respect to the fundamental states, a Pareto improvement could be obtained by allowing dependence on these richer states. From the previous result, the answer is negative.

Whereas conditional and interim optimality coincide in this set up, conditional optimality, at least as we have just defined, is not an adequate criterion in most economies. Even in economies with a time invariant structure for which a natural state can be defined, this state typically includes endogenous variables, such as the distribution of the securities across agents (except under special cases such as two period-lived agents) or the stock of capital. In contrast with interim optimality, conditional optimality, which takes the state as given, does not evaluate the impact of a change in the endogenous variables.

Finally note that the dominant root condition characterizes conditional optimality : If the dominant root is strictly larger than 1, the allocation is not conditionally optimal, and therefore not interim optimal. This suggests that condition (W) is quite close to be necessary for optimality (see also ChattopadhyayGottardi [15] on this point).

\section{Optimality of equilibria}

We study here the optimality of an equilibrium in an economy where agents receive some (random) endowments, transact an infinitely lived asset, "land", and possibly some financial securities in zero supply.

\subsection{An economy with productive land}

We consider an exchange economy, ${ }^{15}$ with two kinds of resources, land and private endowments. Land is an infinitely lived asset in fixed supply which distributes (random) dividends at all periods, $d_{t}$ at $t$. It is said to be productive

\footnotetext{
${ }^{14}$ At a time invariant allocation, the utility level of a type $m$ agent born in state $s$ is well defined. So a time invariant allocation is conditionally optimal is there is no other feasible time invariant allocation for which all the "conditional" utility levels of all agents could be increased.

${ }^{15}$ The analysis is readily extended to the case where production is performed under constant returns to scale or under sequentially complete markets. Otherwise, a profit criterium for a firm is undefined.
} 
if dividends are uniformly bounded below by some stricly positive $\underline{d}: d_{t} \geq \underline{d}$ any $t \geq 0$.

Resources. Agent $i$ receives endowments, $w_{i, t}$, which are non negative, and null if agent does not live at $t$. At the initial date 0 , before the exchanges, agents who were born before hold the land asset; their endowments at date 0 include the returns of their previous investments and the receipts of the risk sharing arrangements that they have contracted among themselves.

Aggregate resources at $t$, which are given by $\omega_{t}=\sum_{i} w_{i, t}+d_{t}$, are assumed to be uniformly bounded above. A state of the world at date $t$ is described by the sequence of the realized private endowments and land dividends from date 0 up to $t$.

Securities. Agents transact the land asset and some financial securities. Financial securities that pay off in the consumption good allow agents living at two consecutive dates to share risks associated with the next period. Assume, as typical in the incomplete markets literature, that these contracts are exogenous, and in a limited number $J:^{16}$ a unit of contract $j$, contracted at time $t$, yields a (random) amount $a_{t+1}^{j}$ of consumption good at $t+1$. Payoffs at $t+1$ are measurable with respect to the state at $t+1$. Let $p_{t}$ denote the price of land at $t, q_{t}=\left(q_{t}^{j}\right)$ the vector of security prices at $t$, and $a_{t+1}=\left(a_{t+1}^{j}\right)$ the security returns at $t+1$.

Transfers. The government may operate some transfers, which are assumed to be implemented at birth (we comment this assumption below): agent $i$ receives $r_{i, t}$ at $t=t_{i}$, which may be positive or negative, and $r_{i, t}=0$ at $t \neq t_{i}$. Transfers must be balanced, $\sum r_{i, t}=0$ for each $t$, and measurable with respect to information. We denote by $\mathbf{r}=\left(r_{i, t}, i, t=0, \ldots\right)$ the process of transfers.

Agents' budget constraints. Let $x_{i, t}$ and $y_{i, t}=\left(y_{i, t}^{j}\right)$ be the share in land and the portfolio of securities that agent $i$ holds at $t$ after the exchanges. Accordingly, if agent $i$ was born before date $0, x_{i,-1}$ is set equal to his initial land holding, and $y_{i,-1}$ is null; if he is born at or after date 0 , he holds no portfolio before the exchanges at date $t_{i}: x_{i, t_{i}-1}, y_{i, t_{i}-1}$ are null. Given the (random) prices of the land and financial securities, and denoting by . the scalar product, the successive budget constraints that agent $i$ faces are given by :

$$
\left\{\begin{array}{l}
c_{i, t}+p_{t} x_{i, t}+q_{t} . y_{i, t}=w_{i, t}+\left(d_{t}+p_{t}\right) x_{i, t-1}+a_{t} . y_{i, t-1}+r_{i, t}, t=t_{i}, . ., T_{i} \\
\text { where } x_{i, t}, y_{i, t} \text { are measurable and } x_{i, T_{i}}=0, y_{i, T_{i}}^{j}=0 .
\end{array}\right.
$$

To require the portfolio at date $T_{i}$ to be null is crucial : otherwise, agent $i$ is willing to borrow as much as possible at the last period of his life.

\subsection{Equilibria with sequentially complete markets}

We consider an equilibrium in which agents correctly expect their budget constraints, i.e. the future prices, and there is complete information on the state of the world.

\footnotetext{
${ }^{16}$ This is merely for notational convenience. Since the security returns are not required to be linearly independent, assuming a fixed number of securities only amounts to assume that their number is uniformly bounded.
} 
Definition 6 Given some transfers $\mathbf{r}$, a rational expectation equilibrium (REE) is formed with a feasible allocation $\mathbf{c}$, measurable price processes for the land $p=\left(p_{t}, t=0, \ldots\right)$ and the financial securities $q^{j}=\left(q_{t}^{j}, t=0, \ldots\right)$ that satisfy

1. for any $i$, any state $s^{t_{i}}$ at birth $t_{i}$, agent $i$ 's consumption plan maximizes $E\left[u_{i}\left(c_{i}\right) \mid s^{t_{i}}\right]$ over the portfolios that satisfy the constraints $(C)$, where prices are correctly expected

2. markets clear at each date, any state $s^{t}: \sum_{i} x_{i, t}=1, \sum_{i} y_{i, t}=0$

Markets are sequentially complete if, for each state $s^{t}$, the space that is spanned by the returns of the financial securities and the land, $\left(a_{t+1}^{j},\left(d_{t+1}+\right.\right.$ $\left.p_{t+1}\right)$ ), is of dimension equal to the number of states $s^{t+1}$ that follow $s^{t}$. Recall that $X_{i}$ denotes $i$ 's unconstrained consumption set.

Theorem 3 Consider a rational expectations equilibrium in an economy with productive land, and complete information. If markets are sequentially complete and the equilibrium allocation is short run $(\mathbf{e}, \mathbf{X})$-optimal, then it is $(\mathbf{e}, \mathbf{X})$ optimal as well.

Corollary Consider a rational expectations equilibrium in an economy with productive land, and complete information. If markets are sequentially complete, the equilibrium allocation is interim $\mathbf{X}$-optimal.

The proof of Theorem 3 is a direct application of Theorem 1, by using the fact that condition (S) is surely satisfied. ${ }^{17}$

A positive implication of Theorem 3 is that, under the stated assumptions and as far as optimality is concerned, the intervention of a government is justified only to restore short run optimality. With sequentially complete markets this means to improve risk sharing between generations. Otherwise, no intervention is necessary, as stated by the Corollary : sequentially complete markets allow living agents to optimally trade, so that an equilibrium is short run interim $\mathbf{X}$ optimal. ${ }^{18}$ This result generalizes a well known result obtained in OLG models without uncertainty. This is however no longer true whenever utility levels are evaluated before birth, i.e. if $e_{i}<t_{i}$ for some $i$. An equilibrium has few chance to be short run $(\mathbf{e}, \mathbf{X})$-optimal : agents cannot trade before their birth so that markets do not allow for insurance against the events at birth. By implementing adequate non distortionary transfers among a finite number of generations, risk sharing may be improved. It is easily shown that, with sequentially complete markets, these transfers can always be implemented at birth, which justifies our assumption.

Since fiat money is an infinitely lived asset similar to land except that its dividends are null, one may wonder whether similar optimality results hold at a REE with money. It is indeed the case if the price of money is positively

\footnotetext{
${ }^{17}$ If $Q$ is a supporting process, land prices satisfy : $Q_{0} p_{0}=E\left[\sum_{\tau=1}^{t} Q_{\tau} d_{\tau}+Q_{t} p_{t}\right]$ any $t$ so that, using that dividends are larger than some positive $\underline{d}$, condition (S) follows.

${ }^{18}$ It suffices to apply standard results to the finite economies composed with all agents born before a given date, and in which there are as many agents $i$ as possible states at birth.
} 
bounded below (and the additional assumptions of Theorem 2) since then condition (W) is met (see Demange-Laroque [6] for similar results in a stationary economy). However, whether an equilibrium with fiat money exists depends in a non trivial way on preferences and endowments, and even if it does, other equilibria in which money is not transacted typically exist; accordingly, if productive land is not transacted, interim optimality is not guaranteed even with complete markets.

If markets are incomplete, the standard approach, and Theorem 1, cannot be applied except in few circumstances. It is enough for our purpose to consider a two period OLG model. Given the transfers $\mathbf{r}$ and an associated equilibrium price $p$, a consumption plan of an agent $i$ born at $t$ belongs to the set $C_{i}^{p}$ :

$$
\begin{aligned}
& C_{i}^{p}=\left\{c_{i}=\left(c_{i, t}, c_{i, t+1}\right) \text {, s.t. } c_{i, t+1}=w_{i, t+1}+\left(d_{t+1}+p_{t+1}\right) x_{i, t}+a_{t+1} \cdot y_{i, t},\right. \\
& \text { for some measurable } \left.x_{i, t}, y_{i, t}\right\}
\end{aligned}
$$

$C_{i}^{p}$ is a convex subset of $X_{i}$ so that, by the same arguments as for Theorem 3 , an equilibrium is interim $\mathbf{C}^{\mathbf{p}}$-optimal. This result is however rather weak, and one would like to assess the effect of the transfers on optimality, which means to compare the equilibrium allocations that are obtained for different transfers. Changing the transfers induces changes in the demand for land, which typically affect its price, and the sets $\mathbf{C}^{\mathbf{p}}{ }^{19}$ As a result, if the government takes into account this equilibrium effect, the consumption sets $\mathbf{C}^{\mathbf{p}}$ at the given equilibrium price are no longer relevant. Taking the union of the sets over various prices does not make sense since the consumption plans of different agents are interdependent, and moreover the union is not convex. This problem is at the root of the generic constrained inefficiency of an equilibrium when markets are incomplete (Geanakoplos-Polemarchakis [8]). In economies with a finite horizon, non convexity arises except in the case of a single consumption good and two dates since then the spanning is exogenous given by the securities payoffs. In an OLG setup such as here, it occurs even if agents live for two periods only since the sharing possibilities of an agent are affected by the future land price, which is itself affected by the future transfers. In such a case short run optimality is no longer characterized by the existence of a supporting process, and Theorem 1 cannot be applied. In the following section, we show however that an equilibrium with land still satisfies some optimality properties.

If information is incomplete, Theorem 3 of course extends to the situation where agents and the planner share the same information, and markets are sequentially complete with respect to that information: it suffices to redefine the state of the world. But presumably agents have some private information, say on their endowments, that the planner does not have. A rather extreme situation is one where agents have full information on the state of the world. Of course the transfers must be measurable with respect to the information

\footnotetext{
${ }^{19}$ In some cases however this does not occur. For example let each generation be composed with several agents that are identical except that they suffer from idiosyncratic shocks on their endowments. If only aggregate endowment is observable and markets are complete with respect to that information, consumption sets $C_{i}^{p}$ are not affected by transfers.
} 
available when they are implemented. Then Corollary of Theorem 3 extends. ${ }^{20}$ However, if the government uses a stronger criterium, say ex ante utility the result is no longer true. The reason is quite similar to the incomplete market case: transfers and equilibrium prices are correlated, and since all transfers are not admissible, the set of consumption plans of an agent is not convex.

\section{Two period life models with incomplete markets}

We focus here on interim optimality in two period life OLG models with possibly incomplete markets. In what follows, an agent $i$ who is born at date $t$ dies at $t+1$; the set of agents born at $t$ is the generation $\mathcal{G}_{t}$.

\subsection{Equilibrium with land}

It is natural to ask whether the interim optimality of an equilibrium with land and sequentially complete markets, extends to incomplete markets in a second best or constrained sense. Here, keeping the returns of the financial securities fixed, we compare the equilibrium allocations that are obtained when some transfers vary. Of course, some restriction must be imposed on the transfers under consideration to get some optimality result: If, starting from an equilibrium allocation with incomplete markets, transfers could be performed without constraints among the old agents, almost surely the lack of risk sharing opportunities could be exploited so as to improve the standing allocation. Therefore, we stick to the assumption that transfers are implemented at birth only. ${ }^{21}$

The government may perform lump sum transfers, and also reallocate the financial securities among the young agents of a given generation. Accordingly, agent $i$ born at $t$ receives lump sum $r_{i, t}$, and an endowment of the financial securities $z_{i, t}=\left(z_{i, t}^{j}\right)$; since transfers at date $t$ are implemented among the young members of generation $\mathcal{G}_{t}$, they satisfy the feasibility conditions : $\sum_{i \in \mathcal{G}_{t}} r_{i, t}=0$ and $\sum_{i \in \mathcal{G}_{t}} z_{i, t}=0$. Transfers are therefore characterized by the process $\mathbf{r}=$ $\left(r_{i, t}, i \in \mathcal{G}_{t}, t=0, \ldots\right)$ and $\mathbf{z}=\left(z_{i, t}, i \in \mathcal{G}_{t}, t=0, \ldots\right)$.

An equilibrium is defined accordingly. We also consider a short sales condition on land, which means here that young agents can only buy land.

Given some transfers $(\mathbf{r}, \mathbf{z})$, an equilibrium with (resp. without) short sales on land is formed with a feasible allocation $\mathbf{c}$, measurable price processes for the land $p=\left(p_{t}, t=0, \ldots\right)$ and the financial securities $q=\left(q_{t}=\left(q_{t}^{j}\right), t=0, \ldots\right)$ that satisfy

$$
\text { 1. for any old agent } i \text { at date } 0: c_{i, 0}=w_{i, 0}+x_{i,-1}\left(p_{0}+d_{0}\right)
$$

\footnotetext{
${ }^{20}$ The allocation is interim $\mathbf{X}$-optimal, and supported by a process $Q$. If $E u_{i}\left[c_{i} \mid h\right]$ can be increased, necessarily $E u_{i}\left[c_{i} \mid s^{t}\right]$ can be increased for at least one state in $h$, which implies that $r_{i}(h)$ is positive. Since this must hold for any agent born at that date, this contradicts the feasibility of the transfers.

${ }^{21}$ At the initial date, transfers could be implemented between the young and the old agents without modifying risk sharing among the old agents, and a slight modification of the proof shows that Theorem 3 is still valid.
} 
for any $i$ born at $t, t \geq 0$, any $s^{t}$, agent $i$ maximizes $E\left[u_{i}\left(c_{i}\right) \mid s^{t}\right]$ over consumption plans that satisfy

$$
\left\{\begin{array}{l}
c_{i, t}+p_{t} x_{i, t}+q_{t} \cdot y_{i, t}=w_{i, t}+r_{i, t}+q_{t} . z_{i, t} \\
c_{i, t+1}=w_{i, t+1}+x_{i, t}\left(p_{t+1}+d_{t+1}\right)+a_{t+1} \cdot y_{i, t} \\
\text { for some portfolio } x_{i, t}, y_{i, t}\left(\text { resp. with } x_{i, t} \geq 0\right)
\end{array}\right.
$$

2. markets clear at each date, any state $s^{t}: \sum_{i} x_{i, t}=1, \sum_{i} y_{i, t}=0$.

Theorem 4 extends, in a constrained sense, the interim optimality of an equilibrium with land and sequentially complete markets (Corollary of Theorem $3)$, to the case of incomplete markets.

Theorem 4 In a two period life overlapping generations economy with productive land and financial securities, let $\mathbf{c}$ be an equilibrium allocation (with or without short sales) associated with transfers $(\mathbf{r}, \mathbf{z})$. If $\mathbf{c}^{\prime}$ is an equilibrium sustained by transfers $\left(\mathbf{r}^{\prime}, \mathbf{z}^{\prime}\right)$ and without short sales on land, then $\mathbf{c}^{\prime}$ does not interim Pareto dominate c.

By the clearing condition, young agents, on aggregate, buy land. A short sales constraint is therefore likely not to be binding. Also, it is surely not binding with a representative agent by period; therefore Theorem 4 extends Abel and alii [1] to heterogeneous population and incomplete markets. By the same remark, with a re From Theorem 4, if short sales are forbidden, any equilibrium allocation is interim optimal among the equilibrium allocations.

If, starting from an equilibrium and modifying transfers, land price was not affected by the transfers, the proof would be easy : both the spanning and the aggregate exchanges between the old and young agents at a given date, which operate through the land asset only, would be unaffected; hence a welfare improvement could be obtained only by a reallocation among the members of a given generation through a change in securities prices and portfolios, which is impossible at an equilibrium (equivalently, using the sets $\mathbf{C}^{\mathbf{p}}$ introduced in the previous sections, an equilibrium is $\mathbf{C}^{\mathbf{p}}$-optimal. But typically modifying transfers has an impact on land price, which affects both the risk sharing opportunities of the young agents and the level of the aggregate transfers between generations. From the above discussion, it is in this change only that a Pareto improvement can be found. However, the first date at which the new equilibrium differs, the price of land must be increased, since otherwise the old agents would suffer. Then, to be Pareto improving, one may show that the expected land prices at the new equilibrium would have to grow unbounded, where the expectation is taken with respect to a convenient probability distribution, with a density with respect to the original probability made up with a combination of the marginal rates of substitution of the young agents. The basic intuition for the result is that, at the initial equilibrium, marginal rates of substitution are, on average, smaller than 1.

\subsection{Equilibrium with Social Security}

A pay-as-you-go Social Security system specifies the compulsory amounts that are transferred from the young agents to the old ones. In a risk-free economy, 
such a system may lead to a Pareto improvement upon the autarkic equilibrium. It is however not true under some interest rates condition. In a two period OLG economy with uncertainty and possibly incomplete markets, we show that an analogous result holds, under some condition on the returns of the financial securities.

As is often the case in practice, we assume that old agents receive a pension in proportion of their previous contribution : Let $m_{t}$ be the aggregate contribution of generation $\mathcal{G}_{t}$ to the system at date $t$, given the state; a member of this generation who contributes a fraction $f$, i.e. gives $f m_{t}$, is entitled to a pension equal to the fraction $f$ of the aggregate contribution of next generation, i.e. to $f m_{t+1}$. At the initial date 0 , the living old agents receive the contribution $m_{0}$ of the current young agents in some specified proportions $f_{i,-1}$. A Social Security system is therefore characterized by $\mathbf{m}=\left(m_{t}, t=0, \ldots\right)$, the process of aggregate contributions of each generation, and $\mathbf{f}=\left(f_{i, t}, i \in \mathcal{G}_{t}, t=-1,0 \ldots\right)$ the nonnegative process that specifies in which proportion members of a given generation participate to the system, where $\sum_{i \in \mathcal{G}_{t}} f_{i, t}=1$. An equilibrium is defined as follows.

Given financial securities $\mathbf{a}$, transfers $(\mathbf{r}, \mathbf{z})$, and a Social Security system $(\mathbf{m}, \mathbf{f})$, an equilibrium is formed with a feasible allocation $\mathbf{c}$, and a measurable security price process $q=\left(q_{t}=\left(q_{t}^{j}\right), t=0, \ldots\right)$ that satisfy

1. for any old agent at date $0, c_{i, 0}=w_{i, 0}+f_{i,-1} m_{0}$

for any $i$ born at $t \geq 0$, any state $s^{t}$ at $t$, agent $i$ 's consumption plan maximizes $E\left[u_{i}\left(c_{i}\right) \mid s^{t}\right]$ over consumption plans that satisfy

$$
\left\{\begin{array}{l}
c_{i, t}+q_{t} . y_{i, t}=w_{i, t}-f_{i, t} m_{t}+r_{i, t}+q_{t} . z_{i, t}, \\
c_{i, t+1}=w_{i, t+1}+f_{i, t} m_{t+1}+a_{t+1} \cdot y_{i, t}, \text { for some } y_{i, t}
\end{array}\right.
$$

2. markets clear at each date, any state $s^{t}: \sum_{i} y_{i, t}=0$.

We now state a condition that bears on the successive returns of financial securities. A portfolio $y=\left(y^{j}\right)$ at $t$, state $s^{t}$ has a strictly positive payoff if $a_{t+1} . y>0$ in any state at $t+1$ following $s^{t}$; its (random) gross return is defined as

$$
R_{t+1}=\frac{a_{t+1} \cdot y}{q_{t}\left(s^{t}\right) \cdot y}
$$

Condition $(R)$ is satisfied at an equilibrium if there is a measurable process $\left(y_{t}, t=0, \ldots\right)$ of portfolios with strictly positive payoffs, such that the product of the returns from date 0 up to $t: \pi_{\tau=0}^{t} R_{\tau}$ tends almost surely to infinity when $t$ tends to infinity.

Clearly, condition $(\mathrm{R})$ is satisfied at a stationary allocation in Samuelson model when the interest rate is above the population growth: Also, in the time invariant model of Section 3.3, (R) is met if the dominant root of the matrix $B$ made up with the marginal rates of substitution is strictly less than 1 .

The optimality of the autarkic equilibrium in Samuelson model under the interest rate condition extends as follows. 
Theorem 5 Consider a two period life overlapping generations economy with financial securities $\mathbf{a}$. Let $\mathbf{c}$ be an equilibrium allocation associated with transfers $(\mathbf{r}, \mathbf{z})$, and no Social Security $(\mathbf{m}=\mathbf{0})$ and $\mathbf{c}^{\prime}$ an equilibrium allocation associated with transfers $\left(\mathbf{r}^{\prime}, \mathbf{z}^{\prime}\right)$ and Social Security system $\left(\mathbf{m}^{\prime}, \mathbf{f}^{\prime}\right)$. If condition $(R)$ is satisfied at $\mathbf{c}$, then $\mathbf{c}^{\prime}$ does not interim Pareto dominate $\mathbf{c}$.

In other words, condition $(\mathrm{R})$ guarantees that an autarkic equilibrium is second best optimal, in a world where a planner can only introduce a "fair" Social Security system, and reallocate the good and the financial securities. This may be surprising since such a system introduces a new risk sharing opportunity, which unambiguously enlarges the spanning.

Note that we do not require the contributions to be nonnegative. But, arguing as previously, a Pareto improvement is possible only if some intergenerational transfers are implemented, $\left(m^{\prime}\right.$ differs from 0$)$, and at any date in any state where it starts to be implemented, it must be positive since otherwise surely old agents would suffer. Later on, for the generations to be not worse off, the expected contributions should grow unbounded, thanks to condition $(\mathrm{R})$, where the expectation is taken with respect to a convenient probability distribution.

\section{Proofs}

Proof of Proposition 1. The proof follows from standard separation arguments. Let $\mathbf{c}$ be an allocation that is optimal for $\mathcal{I}_{t}$. Denote by $T=\max _{i \in \mathcal{I}_{t}} T_{i}$, i.e. all agents born before $t$ die before $T$. Let us consider the economy for which

- there are as many goods as possible states $s^{\tau}$ from $\tau=0$ up to $T$

- agents are the pairs $a=(i, h)$ in which $i$ is born before $t$ and $h$ is a possible information state at date $e_{i}$. The consumption set of agent $a=(i, h)$ is the set $C_{i, h}$, and his preferences are represented by the expected utility of $u^{i}$ given the information $h$. Thanks to the separability of Von Neumann-Morgenstern preferences, and the fact that $i$ 's utility is evaluated no later than birth date, $(i, h),\left(i, h^{\prime}\right)$ care with consumption plans over disjoint sets of states and can be considered as different agents.

- aggregate endowments are equal to those of the initial economy, diminished by the consumption, as given by $\mathbf{c}$, of the agents born after $t$, and also by the investment at the final date, which gives :

$\omega_{\tau}$ if $\tau \leq t, \omega_{\tau}-\sum_{i, t_{i}>t} c_{i, \tau}$ if $t<\tau<T$, and $\omega_{T}-\sum_{i, t_{i}>t} c_{i, T}-k_{T}$ at $T$

- there are as many firms as histories before $T$ : if, $h$ is an information state at $\tau, \tau<T$, firm $h$ chooses investment $k$ at date $\tau$ and produces $f\left(k, \rho_{\tau+1}\right)$ at date $\tau+1$ in all states that may follow $h$ when $\rho_{t+1}$ is realized.

If allocation $\mathbf{c}$ is optimal for $\mathcal{I}_{t}$, its restriction to the agents $\left(i, h^{e_{i}}\right)$ of this artificial economy is Pareto optimal. Under Assumptions A1 this economy satisfies the standard convexity and non satiation assumptions. Therefore, by the second fundamental theorem of welfare economics, there is an equilibrium price vector $\left(p\left(s^{\tau}\right)\right), \tau=0, . ., T$ that supports it. Any positive process $Q$ such that $Q_{\tau}\left(s^{\tau}\right)=p\left(s^{\tau}\right) / P\left(s^{\tau}\right)$ for $\tau \leq \mathcal{T}$ is in $\mathcal{Q}_{t}$. 
The proof of Theorem 1 uses the following lemma.

Lemma 1 Let $\mathbf{c}$ and $\mathbf{c}^{\prime}$ be two feasible allocations, and $\boldsymbol{\Delta} \mathbf{c}=\mathbf{c}^{\prime}-\mathbf{c}$. Given $t$ let $T=\max _{i \in \mathcal{I}_{t}} T_{i}$. If $Q$ is a value process, then :

$$
E\left[\sum_{i \in \mathcal{I}_{t}} Q \Delta c_{i}\right]+E\left[\sum_{t+1}^{T} Q_{\tau}\left(\sum_{i, t_{i}>t} \Delta c_{i, \tau}\right)\right]+E\left[\sum_{0}^{T} \Delta \pi_{\tau}\right]+Q_{T}\left(k_{T}^{\prime}-k_{T}\right)=0
$$

where $\Delta \pi_{\tau}=E\left[Q_{\tau+1} f\left(k_{\tau}^{\prime}, \rho_{\tau+1}\right)-Q_{\tau} k_{\tau}^{\prime}\right]-\left[Q_{\tau+1} f\left(k_{\tau}, \rho_{\tau+1}\right)-Q_{\tau} k_{\tau}\right]$.

Proof of Lemma 1. The allocation $\mathbf{c}^{\prime}$ satisfies the scarcity constraints:

$$
c_{\tau}^{\prime}+k_{\tau}^{\prime}=f\left(k_{\tau-1}^{\prime}, \rho_{\tau}\right)+\omega_{\tau}
$$

Let $Q$ be in $\mathcal{Q}_{t}$. Multiplying the scarcity constraints at time $\tau$ by $Q_{\tau}$, adding them from date 0 up to date $T$ and taking expectation at date 0 , one gets

$$
E\left[\sum_{\tau=0}^{T} Q_{\tau} c_{\tau}^{\prime}\right]+E\left[\sum_{\tau=0}^{T} Q_{\tau+1} f\left(k_{\tau}^{\prime}, \rho_{\tau+1}\right)-Q_{\tau} k_{\tau}^{\prime}\right]+E\left[Q_{T} k_{T}^{\prime}\right]=E\left[\sum_{\tau=0}^{T} Q_{\tau} \omega_{\tau}\right]
$$

The same equation holds true for the allocation $\mathbf{c}$, hence taking the difference yields

$$
E\left[\sum_{\tau=0}^{T} Q_{\tau} \Delta c_{\tau}\right]+E\left[\sum_{0}^{T} \Delta \pi_{\tau}\right]+Q_{T}\left(k_{T}^{\prime}-k_{T}\right)=0
$$

Equation (4) differs from (3) only through the first terms. For $\tau \leq t$ all consumers were surely born before $t$ so that aggregate consumption at date $\tau$ is exactly equal to the aggregate consumption of agents in $\mathcal{I}_{t}$. This is not exactly true after $t$, since then aggregate consumption includes the consumption of the agents who are born after $t$. Therefore $c_{\tau}=\sum_{i \in \mathcal{I}_{t}} c_{i, \tau}$ if $\tau \leq t$ and $c_{\tau}=\sum_{i \in \mathcal{I}_{t}} c_{i, \tau}+\sum_{i, t_{i}>t} c_{i, \tau}$ if $\tau>t$ and similarly for $\mathbf{c}^{\prime}$. So taking the difference and rearranging terms gives:

$$
E\left[\sum_{0}^{T} Q_{\tau} \Delta c_{\tau}\right]=E\left[\sum_{i \in \mathcal{I}_{t}} Q . \Delta c_{i}\right]+E\left[\sum_{t+1}^{T} Q_{\tau}\left(\sum_{i, t_{i}>t} \Delta c_{i, \tau}\right)\right]
$$

which proves $(3)$.

Lemma 2 Assume that $E\left[u_{1}\left(c_{1}^{\prime}\right) \mid h^{0}\right]>E\left[u_{1}\left(c_{1}\right) \mid h^{0}\right]$. Then there is $\delta>0$ such that for any $t \geq 0$ in $f_{Q \in \mathcal{Q}_{t}} E\left[Q \cdot\left(c_{1}^{\prime}-c_{1}\right)\right] \geq \delta$.

Proof of Lemma 2. Since the sets $\mathcal{Q}_{t}$ are decreasing it suffices to prove the property for $t=0$. Recall that agent 1 lives at date 0 and that $E\left[Q \cdot c_{1}\right]=1$ for any $Q \in \mathcal{Q}_{0}$. Given a process $Q$ in $\mathcal{Q}_{0}$ let us consider $P$ its orthogonal projection on the finite dimensional subspace spanned by the set $C_{1}-\left\{c_{1}\right\}$. Then $E\left[P .\left(x_{1}-c_{1}\right)\right]=E\left[Q .\left(x_{1}-c_{1}\right)\right]$ for any $x_{1}$ in $C_{1}$. One deduces that $E\left[Q \cdot\left(c_{1}^{\prime}-c_{1}\right)\right]=E\left[P .\left(c_{1}^{\prime}-c_{1}\right)\right]$ and that $P$ satisfies:

if $x_{1}$ is in $C_{1}$ and $E\left[u_{1}\left(x_{1}\right)\right]>E\left[u_{1}\left(c_{1}\right)\right]$ then $E\left[P . x_{1}\right]>E\left[P . c_{1}\right]$, which says that $P$ belongs to the positive cone that "supports" $c_{1}$. Using the normalization $E\left[Q . c_{1}\right]=1$, it implies that $P$ belongs to a compact set $\mathcal{P}$. 
Therefore surely inf $f_{P \in \mathcal{P}} E\left[P .\left(c_{1}^{\prime}-c_{1}\right)\right]$ is strictly positive. Since $i n f_{P \in \mathcal{P}} E\left[P .\left(c_{1}^{\prime}-\right.\right.$ $\left.\left.c_{1}\right)\right]=i n f_{Q \in \mathcal{Q}_{t}} E\left[Q \cdot\left(c_{1}^{\prime}-c_{1}\right)\right]$, this gives the result.

Proof of Theorem 1. Let $\mathbf{c}$ be a bounded allocation that satisfies short run e-optimality and the transversality condition. By contradiction consider some C-feasible allocation $\mathbf{c}^{\prime}$ that weakly dominates $\mathbf{c}$. Thanks to assumption A1 (ii), one may assume that agent 1 is strictly better off. If it is not the case, there is an agent $i$ who is strictly better off given information $h$ at $e_{i}$. Let $h^{t_{i}}$ be an information set that follows $h$ at date $t_{i}$ (if $e_{i}=t_{i}$, then $h=h^{t_{i}}$ ). By A1 (ii) and continuity of preferences, for small enough $\epsilon>0, c_{i, h}^{\prime}-\epsilon \mathbb{1}\left(h^{t_{i}}\right)$ is feasible and preferred to $c_{i, h}$ by agent $(i, h)$. Now there is an agent $j$ who lives at dates $t_{i}-1$ and $t_{i}$. Let $h^{\prime}$ be the unique history at date $e^{j}$ that precedes $h^{t_{i}}$. Thanks to A1 (ii) again, one may add $\epsilon \mathbb{1}\left(h^{t_{i}}\right)$ to $c_{j, h^{\prime}}^{\prime}$ (or little less if necessary for feasibility) and make agent $\left(j, h^{\prime}\right)$, who is born before $i$, strictly better off than at $c_{j, h^{\prime}}$. Continuing backward, agent 1 can be made better off.

Now let us consider date $t$ and a process in $\mathcal{Q}_{t}$. Since $\mathbf{c}^{\prime}$ dominates c, surely $E\left[Q .\left(c_{i, h}^{\prime}-c_{i, h}\right)\right] \geq 0$ for any agent in $\mathcal{I}_{t}$, so that adding over all possible histories $h$ at date $e_{i}: E\left[Q \cdot\left(c_{i}^{\prime}-c_{i}\right)\right] \geq 0$. Similarly $E\left[\Delta \pi_{\tau}\right] \geq 0$. Therefore, using (3) of Lemma 1 and Lemma 2, we get that for some $\delta>0$, which is independent of $t$ and $Q$,

$$
\delta+E\left[\sum_{\tau=t+1}^{T} Q_{\tau}\left(\sum_{i, t_{i}>t} c_{i, \tau}^{\prime}-c_{i, \tau}\right)+Q_{T}\left(k_{T}^{\prime}-k_{T}\right)\right] \leq 0
$$

Recall that under our assumptions, $\mathbf{c}$ is bounded. Since investment and consumption are nonnegative at the allocation $\mathbf{c}^{\prime}$, surely, for some $B, k_{T}-k_{T}^{\prime} \leq B$ and $c_{i, \tau}-c_{i, \tau}^{\prime} \leq B$ uniformly. Furthermore the number of agents simultaneously alive is uniformly bounded. One deduces that there is some $K>0$ such that

$$
\delta \leq K E\left[\sum_{\tau=t+1}^{t+\ell} Q_{\tau}\right] \text { for any } t \geq 0 .
$$

Now, by condition (S), $\inf _{Q \in \mathcal{Q}_{t}} \sum_{\tau=t+1}^{t+\ell} E\left[Q\left(h^{\tau}\right)\right]$ tends to zero : this gives a contradiction.

Proof of theorem 2. Assume the weak condition (W) together with assumptions A2 to be satisfied. By A2, there is $\beta>0$ such that for any $i$, any consumption vectors $y$ and $x$

$$
u_{i}(y)-u_{i}(x) \leq u_{i}^{\prime}(x) \cdot(y-x)-\beta\|y-x\|^{2} .
$$

Taking expectation knowing $h$, the difference in utilities at the two allocations : $\Delta u_{i}(h)=E\left[u_{i}\left(c_{i, h}^{\prime}\right)-u_{i}\left(c_{i, h}\right) \mid h\right]$ satisfy:

$$
0 \leq \Delta u_{i}(h) \leq E u_{i}^{\prime}\left(c_{i, h}\right)\left(c_{i, h}^{\prime}-c_{i, h}\right)-\beta\left\|c_{i, h}^{\prime}-c_{i, h}\right\|^{2} .
$$

If $Q$ is a supporting process, there is $\lambda>0$ (which depends on $i$ and $h$ ) such that for any feasible $c^{\prime \prime}$

$$
E\left[u_{i}^{\prime}\left(c_{i, h}\right) \cdot\left(c_{i, h}^{\prime \prime}-c_{i, h}\right) \mid h\right]=\lambda E\left[Q\left(c_{i, h}^{\prime \prime}-c_{i, h}\right)\right]
$$


This holds for $c_{i}^{\prime \prime}=c_{i}^{\prime}$, and for $c_{i, h}^{\prime \prime}=c_{i, h}+\epsilon 1_{i, h}$, where $1_{i, h}$ is the consumption plan which gives one unit of the good in each history following $h$ at each date where $i$ lives, and zero otherwise (from A1 it is feasible for $\epsilon>0$ small enough). Therefore, $E\left[u_{i}^{\prime}\left(c_{i, h}\right) \cdot\left(1_{i, h}\right) \mid h\right]=\lambda E\left[Q \cdot\left(1_{i, h}\right)\right]$ and dividing $(7)$ by $\lambda$ gives :

$$
0 \leq \frac{\Delta u_{i}(h)}{\lambda} \leq E Q\left(c_{i, h}^{\prime}-c_{i, h}\right)-\beta \frac{E Q \cdot 1_{i, h}}{E\left[u_{i}^{\prime} \cdot 1_{i, h} \mid h\right]}\left\|c_{i, h}^{\prime}-c_{i, h}\right\|^{2}
$$

To simplify assume first no production. The proof now follows the same line as that of theorem 1. Adding the above inequalities over all agents born before $t$, all histories at birth, inequality (5) is replaced now by

$$
\delta+\beta \sum_{i / t_{i} \leq t}\left(\sum_{h \text { at } e_{i}} \frac{E Q \cdot 1_{i, h}}{E\left[u_{i}^{\prime} \cdot 1_{i, h} \mid h\right]}\left\|c_{i, h}^{\prime}-c_{i, h}\right\|^{2}\right) \leq E\left[\sum_{\tau=t+1}^{T} Q_{\tau}\left(\sum_{i, t_{i}>t} c_{i, \tau}^{\prime}-c_{i, \tau}\right)\right] .
$$

By condition $(\mathrm{W})$, the right hand side is bounded. The left hand side is increasing, and to be bounded, under A2, it is necessary that $E Q .1_{i, h}\left\|c_{i, h}^{\prime}-c_{i, h}\right\|^{2}$ goes to zero when $t_{i}$ increases. But then the right hand side surely goes to zero; a contradiction.

With production, under our assumptions, if $Q$ is a supporting process,

$E\left[Q_{\tau+1} f\left(k_{\tau}^{\prime}, \rho_{\tau+1}\right)-Q_{\tau} k_{\tau}^{\prime}\right]-\left[Q_{\tau+1} f\left(k_{\tau}, \rho_{\tau+1}\right)-Q_{\tau} k_{\tau}\right]-\gamma E\left[Q_{\tau+1}\right]\left(k_{\tau}^{\prime}-k_{\tau}\right)^{2} \leq 0$

and the same type of argument can be used.

Proof of Theorem 4. Let $\mathbf{c}$ and $\mathbf{c}^{\prime}$ be two equilibrium allocations that are associated with lump sum transfers and reallocation of the financial securities among the young agents of a given generation, respectively $\mathbf{r}, \mathbf{z}$, and $\mathbf{r}^{\prime}, \mathbf{z}^{\prime}$. Assume that $\mathbf{c}^{\prime}$ (weakly) dominates $\mathbf{c}$ : For any $t$, any agent $i$ born at date $t$, in any possible state $s^{t}$ at $t$ :

$$
E\left[u_{i}\left(c_{i}^{\prime}\right) \mid s^{t}\right] \geq E\left[u_{i}\left(c_{i}\right) \mid s^{t}\right]
$$

It suffices to show that all inequalities (8) are binding.

Denote $\operatorname{mrs}_{i}=\frac{\partial u_{i}\left(c_{i}\right)}{\partial c_{i, t+1}} / E\left[\frac{\partial u_{i}\left(c_{i}\right)}{\partial c_{i, t}} \mid s^{t}\right]$, the $i^{\prime}$ s marginal rate of substitution for consumption between dates $t$ and $t+1$ at allocation $\mathbf{c}$. Lemma 3 is valid whether short sales are allowed or not at equilibrium $\mathbf{c}$.

Lemma 3 Let us assume that $\mathbf{c}^{\prime}$ dominates $\mathbf{c}$. Then $p_{0}^{\prime}-p_{0} \geq 0$ and at any date $t \geq 0$, any state $s^{t}$

$$
E\left[\sum_{i \in \mathcal{G}_{t}}\left(m r s_{i} x_{i, t}^{\prime}\right)\left(p_{t+1}^{\prime}-p_{t+1}\right) \mid s^{t}\right]-\left(p_{t}^{\prime}-p_{t}\right) \geq 0
$$

Proof of lemma 3. Let us consider a state $s^{t}$, and $i$, a member of generation $\mathcal{G}_{t}$. By concavity of the utility function, $E\left[u^{\prime}\left(c_{i}\right) \cdot\left(c_{i}^{\prime}-c_{i}\right) \mid s^{t}\right] \geq 0$

$$
E\left[\frac{\partial u_{i}\left(c_{i}\right)}{\partial c_{i, t}}\left(c_{i, t}^{\prime}-c_{i, t}\right)+\frac{\partial u_{i}\left(c_{i}\right)}{\partial c_{i, t+1}}\left(c_{i, t+1}^{\prime}-c_{i, t+1}\right) \mid s^{t}\right] \geq 0 .
$$


Since $c_{i, t}^{\prime}-c_{i, t}$ is measurable with respect to $s^{t}$, it may be factored out in the expectation; dividing by the expected marginal utility of consumption at $t$ gives :

$$
\delta_{i}=E\left[\operatorname{mrs}_{i}\left(c_{i, t+1}^{\prime}-c_{i, t+1}\right) \mid s^{t}\right]+\left(c_{i, t}^{\prime}-c_{i, t}\right) \geq 0 .
$$

The differences in consumption come from the differences in transfers at date $t$, the prices and the chosen portfolios. To simplify notation, we drop index $t$ in the portfolios. At date $t$, it may be written as follows :

$$
c_{i, t}^{\prime}-c_{i, t}=-x_{i}^{\prime}\left(p_{t}^{\prime}-p_{t}\right)-y_{i}^{\prime} \cdot\left(q_{t}^{\prime}-q_{t}\right)+\left(y_{i}^{\prime}-y_{i}\right) \cdot q_{t}+\left(x_{i}^{\prime}-x_{i}\right) p_{t}+\alpha_{i}^{\prime}-\alpha_{i}
$$

where $\alpha_{i}=\left(r_{i, t}+q_{t} . z_{i, t}\right)$ is equal to the total value of the transfer at allocation c, and similarly for $\alpha_{i}^{\prime}$. At date $t+1$, when old :

$$
c_{i, t+1}^{\prime}-c_{i, t+1}=x_{i}^{\prime}\left(p_{t+1}^{\prime}-p_{t+1}\right)+\left(y_{i}^{\prime}-y_{i}\right) \cdot a_{t+1}+\left(x_{i}^{\prime}-x_{i}\right)\left(d_{t+1}+p_{t+1}\right)
$$

At equilibrium c, the first order conditions on the portfolio are met. This gives for any financial security :

$$
E\left[\operatorname{mrs}_{i} a_{t+1}^{j} \mid s^{t}\right]-q_{t}^{j}=0, \text { any } j .
$$

As for the land asset, we get either :

$$
E\left[\operatorname{mrs}_{i}\left(d_{t+1}+p_{t+1}\right) \mid s^{t}\right]-p_{t}=0 .
$$

if there are no short sales constraint, or

$$
\left.E\left[\operatorname{mrs}_{i}\left(d_{t+1}+p_{t+1}\right) \mid s^{t}\right]-p_{t}\right) \leq 0, \text { with an equality if } x_{i}>0
$$

if there is a short sales constraint, so that in both cases $E\left[\operatorname{mrs}_{i} x_{i}\left(d_{t+1}+\right.\right.$ $\left.\left.p_{t+1}\right) \mid s^{t}\right]-p_{t}=0$. Using all the above equations, inequality (10) can be rewritten as

$$
\delta_{i}=E\left[\operatorname{mrs}_{i} x_{i}^{\prime}\left(p_{t+1}^{\prime}-p_{t+1}\right) \mid s^{t}\right]-x_{i}^{\prime}\left(p_{t}^{\prime}-p_{t}\right)-y_{i}^{\prime} \cdot\left(q_{t}^{\prime}-q_{t}\right)+\alpha_{i}^{\prime}-\alpha_{i} \geq 0
$$

The equilibrium conditions at date $t, \sum_{i \in \mathcal{G}_{t}} x_{i}=1, \sum_{i \in \mathcal{G}_{t}} y_{i}=0$ and $\sum_{i \in \mathcal{G}_{t}} \alpha_{i}=$ 0 are satisfied, and similarly for the ' values. Summing inequalities (10) over all agents born at $t$ in state $s^{t}$ yields (9).

Consider now an old agent $i$ at date 0 . Then $c_{i, 0}^{\prime}-c_{i, 0}=x_{i,-1}\left(p_{0}^{\prime}-p_{0}\right)$. Since $x_{i,-1}>0$ for at least one old agent, old agents are not worse off only if $p_{0}^{\prime}-p_{0} \geq 0$.

Rest of the proof of theorem 4 Let us first assume that $\mathbf{c}$ is an equilibrium without short sales constraint. Using $\sum_{i \in \mathcal{G}_{t}} x_{i, t}^{\prime}=1$, and the first order condition (12) on land, we get

$$
E\left[\sum_{i \in \mathcal{G}_{t}} \operatorname{mrs}_{i} x_{i, t}^{\prime}\left(\frac{d_{t+1}+p_{t+1}}{p_{t}}\right) \mid s^{t}\right]=1 .
$$

Since $x_{i, t}^{\prime}$ are all nonnegative the function in brackets is a density function with respect to probability $P$. This allows us to define a new transition probability 
from $t$ to $t+1$, and by Tulcea's theorem, a probability measure on the states. Inequalities (9) can be rewritten as

$$
E^{*}\left[\frac{p_{t+1}^{\prime}-p_{t+1}}{p_{t+1}+d_{t+1}} \mid s^{t}\right] \geq \frac{\left(p_{t}^{\prime}-p_{t}\right)}{p_{t}}, t \geq 0
$$

where $*$ denotes the expectation with respect to the new probability. Let the process $\phi$ be defined by $\phi_{0}=1$, and

$$
\phi_{t}=\Pi_{\tau=1}^{\tau=t} \frac{p_{\tau}}{p_{\tau}+d_{\tau}} .
$$

$\phi_{t}$ is measurable with respect to the state at $t$, and satisfies the identity $\phi_{t}\left(p_{t}+\right.$ $\left.d_{t}\right)=p_{t} \phi_{t-1}, t>0$. Therefore, multiplying inequality (16) by $\phi_{t}$, yields

$$
E^{*}\left[\frac{p_{t+1}^{\prime}-p_{t+1}}{p_{t+1}+d_{t+1}} \phi_{t} \mid s^{t}\right] \geq \frac{\left(p_{t}^{\prime}-p_{t}\right)}{p_{t}+d_{t}} \phi_{t-1}
$$

Iterating the above inequality from date 0 gives, by the law of iterated expectation, for any $t>0$ :

$$
E^{*}\left[\frac{p_{t+1}^{\prime}-p_{t+1}}{p_{t+1}+d_{t+1}} \phi_{t} \mid s^{0}\right] \geq E^{*}\left[\frac{p_{t}^{\prime}-p_{t}}{p_{t}+d_{t}} \phi_{t-1} \mid s^{0}\right] \geq \frac{\left(p_{0}^{\prime}-p_{0}\right)}{p_{0}}
$$

We first show that $\phi_{t}$ tends almost surely to zero. Summing the budget equation of the young agents at date $t$ yields that prices $p_{t}$ are uniformly bounded above by the bound on $\omega_{t}$. Since moreover dividends are bounded below, for some $\lambda<1, p_{\tau} /\left(p_{\tau}+d_{\tau}\right) \leq \lambda$ any $\tau$, which gives the result. Therefore the left hand side of (17) tends to zero. Since $\left(p_{0}^{\prime}-p_{0}\right)$ is non negative, it implies that all terms in (17) are identically equal to zero. Going backward, all previous inequalities, in particular (8), are satisfied as equalities, the desired result.

If there is a short sales constraint, the proof follows the same lines. Since (12) is replaced by (13), the expectation in (15) is positive not greater than 1 , equal to some $\lambda_{t}\left(s^{t}\right)$. Therefore the function in brackets divided by $\lambda_{t}\left(s^{t}\right)$ is a density function with respect to probability $P$. Inequalities $(17)$ can be rewritten as

$$
E^{*}\left[\lambda_{t}\left(s^{t}\right) \frac{p_{t+1}^{\prime}-p_{t+1}}{p_{t+1}+d_{t+1}} \mid s^{t}\right] \geq \frac{\left(p_{t}^{\prime}-p_{t}\right)}{p_{t}}, t \geq 0 .
$$

It suffices then to define $\phi_{t}$ as

$$
\phi_{t}=\Pi_{\tau=1}^{\tau=t} \frac{p_{\tau} \lambda_{\tau}}{p_{\tau}+d_{\tau}}
$$

and the proof follows.

Proof of Theorem 5. The proof follows similar arguments as those of Theorem 4 (without short sales constraint). Consider two equilibrium allocations $\mathbf{c}$ and $\mathbf{c}^{\prime}$ that are associated respectively with no social security system and $\mathbf{m}^{\prime}$. Lemma 3 is replaced by :

Lemma 4. Let $\mathbf{c}^{\prime}$ dominate $\mathbf{c}$. Then $m_{0}^{\prime} \geq 0$ and at any date $t \geq 0$, any $s^{t}$ :

$$
E\left[\sum_{i \in \mathcal{G}_{t}} m r s_{i} f_{i, t}^{\prime} m_{t+1}^{\prime} \mid s^{t}\right]-m_{t}^{\prime} \geq 0
$$


Let us consider a portfolio process $y$ as given by condition $(R)$. At equilibrium c, the first order conditions (12) on the financial securities are met. So, let $i$ be born at $t$, in state $s^{t}$; by linearity we get

$$
E\left[\operatorname{mrs}_{i} a_{t+1}^{j} y_{t} \mid s^{t}\right]-q_{t}^{j} y_{t}=0 \text {, any } j .
$$

where $y_{t}$ is the portfolio in $s^{t}$, which simply gives $E\left[\operatorname{mrs}_{i} R_{t} \mid s^{t}\right]=1$. Using $\sum_{i \in \mathcal{G}_{t}} f_{i, t}^{\prime}=1$, taking a linear combination over all the agents born at $t$ yields $\left.E\left[\sum_{i \in \mathcal{G}_{t}} \operatorname{mrs}_{i} f_{i, t}^{\prime}\right) R_{t} \mid s^{t}\right]=1$. Now since the shares $f_{i, t}^{\prime}$ are nonnegative, this allows us to define a new transition probability from $t$ to $t+1$ with a density with respect to the initial one equal to the function $\left(\sum_{i \in \mathcal{G}_{t}} \operatorname{mrs}_{i} f_{i, t}^{\prime}\right) R_{t}$. It then suffices to define the function $\phi_{t}$ as the reciprocal of $\pi_{\tau=1}^{t} R_{\tau-1}$. Under $(\mathrm{R}), \phi_{t}$ tends almost surely to zero, and the proof follows.

\section{REFERENCES}

1. Abel B., Mankiw N., Summers L., and Zeckhauser R. (1989) : 'Assessing Dynamic Efficiency: Theory and Evidence', Review of Economic Studies, $56,1-18$.

2. Aliprantis C.D., Brown D.J., and Burkinshaw O. (1990) : 'Valuation and optimality in the overlapping generations model', International Economic Review, Vol 31, 2, 275-288.

3. Aiyagari, S.R. and D. Peled (1991) : 'Dominant Root Characterization of Pareto Optimality and the Existence of Monetary Equilibria in Stochastic Overlapping Generations Models', Journal of Economic Theory, 54, 6983.

4. Borch, K. (1960) : 'The Safety Loading of Reinsurance Premiums', Skandinavrsk Aktuarieskrift, 153-84.

5. Chattopadhyay, S and P. Gottardi (1999) : Stochastic OLG models, market structures, and optimality, Journal of Economic Theory.

6. Demange, G. and G. Laroque (1999) : 'Social Security and demographic shocks', Econometrica 67, 527-542.

7. Diamond P. (1965): 'National Debt in a Neoclassical Growth Model', The American Economic Review, 55, 1126-1150.

8. Gale D. (1973) : 'Pure exchange equilibrium of dynamic economic models', Journal of Economic Theory, 5, 12-36.

9. Geanakoplos J., and H. Polemarchakis (1987), "Existence, regularity and constrained suboptimality of competitive allocations when the asset market is incomplete", Uncertainty, information, and communication, Essays in Honor of Keneth Arrow, 3, Cambridge University Press, Heller et al., eds.

10. Geanakoplos J., and H. Polemarchakis (1991) : Overlapping gnerations, Handbook of of Mathematical Economics, IV, Chapter 35, 1899-1962. 
11. Muench, T. (1977) : 'Optimality, the interaction of spot and future markets, and the noneutrality of money in the Lucas model ${ }^{6}$, Journal of Economic Theory, 15, 325-344.

12. Okuno M. and I. Zilcha (1980) : 'On the efficiency of a competitive aquilibrium in infinite horizon monetary economies', Review of Economic Studies, Vol XLVII, 797-807.

13. Peled, D. (1984), 'Stationary Pareto Optimality of Stochastic Asset Equilibria with Overlapping Generations', Journal of Economic Theory, 34, 396-403.

14. Samuelson P. (1958), 'An exact consumption-loan model of interest with or without the social contrivance of money', Journal of Political economy, $66,467-482$.

15. Wilson, C.A. (1981): Equilibrium in dynamic models with an infinity of agents, Journal of Economic Theory 24, 95-111.

16. Zilcha I. (1990) 'Dynamic efficiency in overlapping generations models with stochastic production', Journal of Economic Theory 52, 364-379.

17. Zilcha I. (1991) 'Characterizing Efficiency in Stochastic. Overlapping Generations Models', Journal of Economic Theory 55, 1-16. 